13

\title{
Полевая электронная эмиссия с иридиевого острия, покрытого углеродом
}

\author{
(ㄱ Д.П. Бернацкий, В.Г. Павлов \\ Физико-технический институт им. А.Ф. Иофрфе РАН, \\ 194021 Санкт-Петербург, Россия \\ e-mail: bernatskii@ms.ioffe.ru
}

(Поступило в Редакцию 27 марта 2017 г.)

Исследовано образование углеродного покрытия на иридиевом полевом электронном эмиттере при пиролизе паров бензола. Процессы на острийном эмиттере отличаются от изученных ранее на плоских поверхностях металлов. Покрытие получается либо в форме моноатомной графеновой пленки на плоских гранях эмиттера, либо в форме графитовых наростов. Полевая электронная эмиссия локализуется на ребрах и углах ограненного графитового нароста. После адсорбции щелочных металлов на углеродное покрытие происходят аномально большое усиление эмиссии с плоских граней и локализация эмиссии на покрытых графеном гранях при наличии атомов щелочного металла на поверхности и под графеновой пленкой.

DOI: 10.21883/JTF.2017.11.45138.2260

\section{Введение}

Полевые электронные эмиттеры из углеродных материалов обладают рядом полезных эксплуатационных свойств [1-3]. Они более устойчивы по сравнению с эмиттерами из других проводящих веществ по отношению к таким факторам, влияющим на стабильность эмиттера, как адсорбция газов, ионная бомбардировка, изменение формы за счет поверхностной самодиффузии. Многие формы углерода проявляют эффект так называемой „низкополевой“ электронной эмиссии, т. е. эмиссии электронов при существенно более низком электрическом напряжении, чем металлические эмиттеры [2]. К существенным недостаткам углеродных эмиттеров можно отнести сложность их изготовления. Изготовление полевых эмиттеров из углерода, их формовка в вакууме намного сложнее, чем металлических эмиттеров. Технология изготовления металлических эмиттеров в форме острия электролитическим или химическим травлением хорошо отработана и не представляет трудностей. При нагревании в вакууме они очищаются от поверхностных и объемных загрязнений, их поверхность сглаживается за счет поверхностной самодиффузии и формируется гладкая, близкая к полусферической, вершина острия. Изучение роста различных форм углерода на поверхности металлических полевых эмиттеров представляет интересную задачу с точки зрения совмещения достоинств технологии металлических эмиттеров с достоинствами эксплуатационных свойств углеродных эмиттеров. В работах [4-6] исследуются полевые электронные эмиттеры, в которых эмитирующая поверхность создается слоями металла и углерода в форме фуллерена. Показано, что фуллереновое покрытие уменьшает разрушающее действие ионной бомбардировки.

Другой целью исследования роста углеродных образований на поверхности металла является изучение механизмов самопроизвольного появления полевых эмиссионных центров на поверхности металлических электродов в вакууме. Эмиссионные центры в форме наноразмерных углеродных образований могут образовываться при разложении органических молекул на поверхности эмиттера. Локальные эмиссионные центры влияют на электрическую прочность высоковольтных вакуумных промежутков и инициируют взрывную электронную эмиссию [7].

В настоящей работе изучается полевая электронная эмиссия углеродных структур, которые образуются из молекул бензола на иридиевом полевом эмиттере. Иридий выбран в качестве подложки из-за того, что он не образует химических соединений и твердых растворов с углеродом.

Большинство исследований взаимодействия органических молекул с металлами проведено с использованием плоских поверхностей: граней монокристалла или металлических лент, при этом исследуемая поверхность либо полностью, либо преимущественно состояла из одной плотно упакованной кристаллической плоскости. При взаимодействии органических молекул на плоской поверхности каталитически активных металлов образуется монослойная двумерная пленка графена $[8,9]$. После образования пленки графена каталитическое разложение органических молекул с освобождением атомов углерода обычно прекращается и рост многослойного углеродного покрытия не происходит.

В отличие от однородной плоскости эмитирующая поверхность полевого электронного эмиттера в виде острия содержит набор различных кристаллографических плоскостей, их ступеней и переходных областей. Взаимодействие органических молекул с такой поверхностью, как показали предварительные эксперименты [10], может существенно отличаться от взаимодействия с плоскостью. Задачей настоящей работы являлось изучение зависимости образования углеродных покрытий от кристаллографической структуры и 
кривизны поверхности кристалла иридия, определение мест формирования графена и других форм углеродного покрытия, устойчивости углеродных покрытий в электрическом поле и особенностей интеркалирования и полевой десорбции щелочных металлов.

\section{1. Экспериментальная методика}

Для изучения процессов образования графена и других углеродных форм на участках поверхности с различной структурой применялись методики полевой электронной микроскопии, полевой десорбционной микроскопии непрерывного действия и измерения характеристик полевой электронной эмиссии [11]. С помощью данных методов можно изучать структуру и состав поверхности образца и адсорбата, изучать динамику полевой десорбции, измерять величину десорбирующего поля, следить за изменениями работы выхода поверхности. Изменения работы выхода поверхности вычислялись из характеристик Фаулера-Нордгейма для токов полевой электронной эмиссии.

Иридиевые острия изготавливались из иридиевой проволоки путем электрохимического травления в щелочном растворе. Полученное острие отжигалось в вакууме при температуре $T=2500 \mathrm{~K}$, в результате чего на вершине острия формировался монокристалл равновесной формы с радиусом закругления порядка 500-1000 nm. Получение углеродных покрытий на иридии осуществлялось пиролизом бензола, т.е. выдержкой нагретого иридия $(T=1200-1900 \mathrm{~K})$ в парах бензола (при давлении $p=10^{-8}-10^{-5}$ Torr) [12]. Использование этой методики позволяет получать монослойную графеновую пленку на плоских поверхностях металлов, в том числе на иридии.

\section{2. Результаты экспериментов}

Поверхность чистого иридиевого острия состоит из плоских кристаллических граней (111) и (100), окружающих их ступеней моноатомной высоты и уменьшающейся по мере удаления от грани ширины. Полевая электронная эмиссия идет преимущественно с переходных областей между гранями и практически отсутствует с плоских граней, что связано с более слабым электрическим полем на плоской поверхности и более высокой работой выхода плотноупакованных плоскостей.

После выдержки эмиттера в парах бензола на поверхности иридия формировалось углеродное покрытие. Фазовый состав и форма покрытия зависели от условий эксперимента (давление паров бензола, температура эмиттера и время экспозиции) и были разными на разных кристаллографических участках поверхности.

\section{1. Образование графена}

При относительно малых экспозициях на плоских плотноупакованных гранях росли двумерные графено- вые островки или формировалась моноатомная пленка графена, покрывающая всю плоскость. При этом на других участках поверхности находились отдельные атомы углерода и их скопления. Работа выхода графеновой пленки на иридии, вычисленная из характеристик Фаулера-Нордгейма, составляла $4.4 \pm 0.1 \mathrm{eV}$.

На рис. 1, $a$ приведено полевое электронное изображение иридиевого полевого эмиттера после выдержки в парах бензола ( $p=1 \cdot 10^{-6}$ Torr, $\left.T=1600 \mathrm{~K}, t=2 \mathrm{~min}\right)$. В центре рисунка видна грань (100), на которой расположены островки, образовавшиеся при экспозиции нагретого острия в парах бензола. Усиление полевой электронной эмиссии с островков связано с более низкой работой выхода графена по сравнению с работой выхода иридия. Эмиссия с остальной поверхности острия
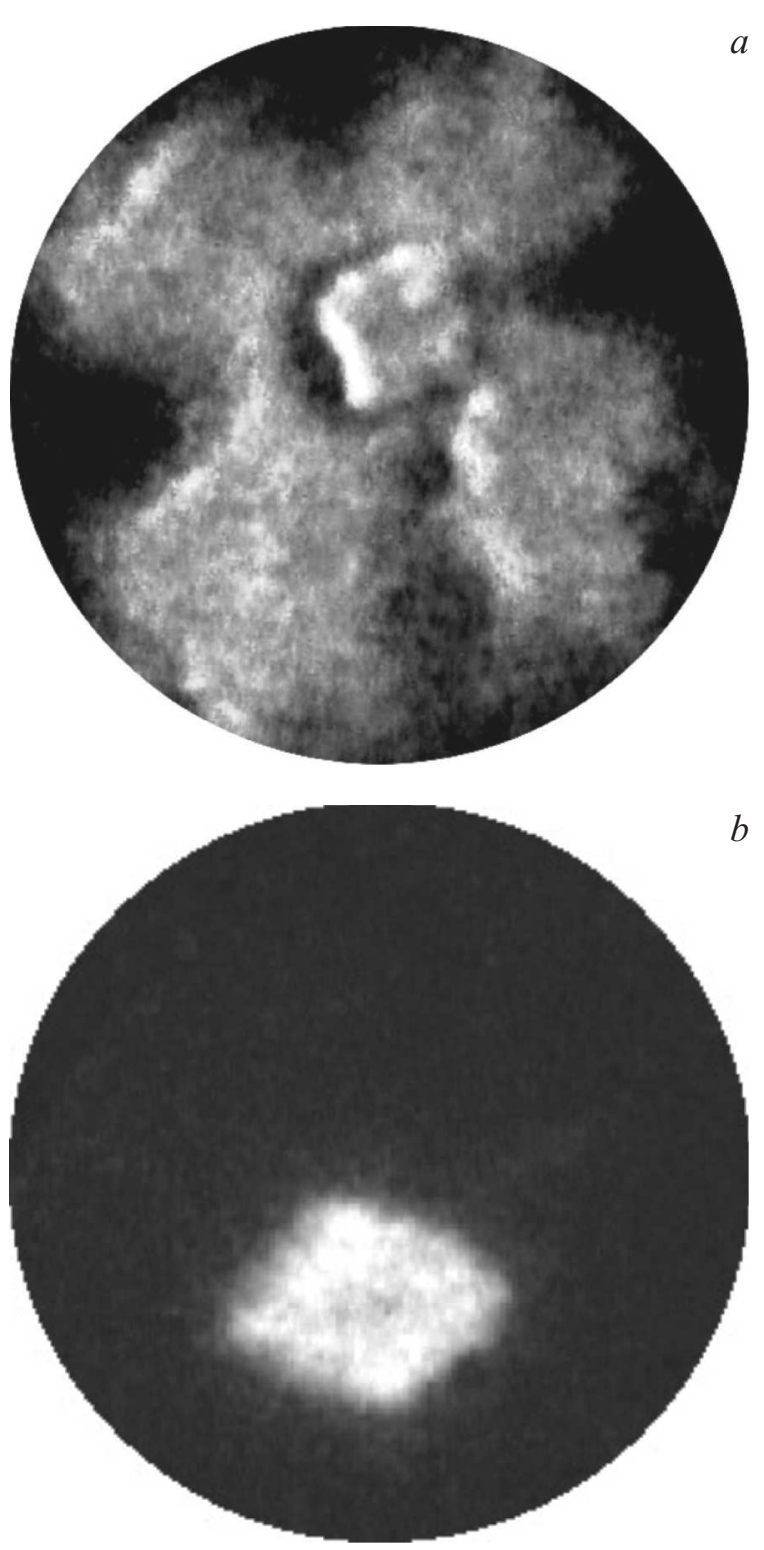

Рис. 1. Полевое электронное изображение иридиевого острия с островками графена на плоскости (100) (a) и углеродом и цезием на поверхности $(b)$. 


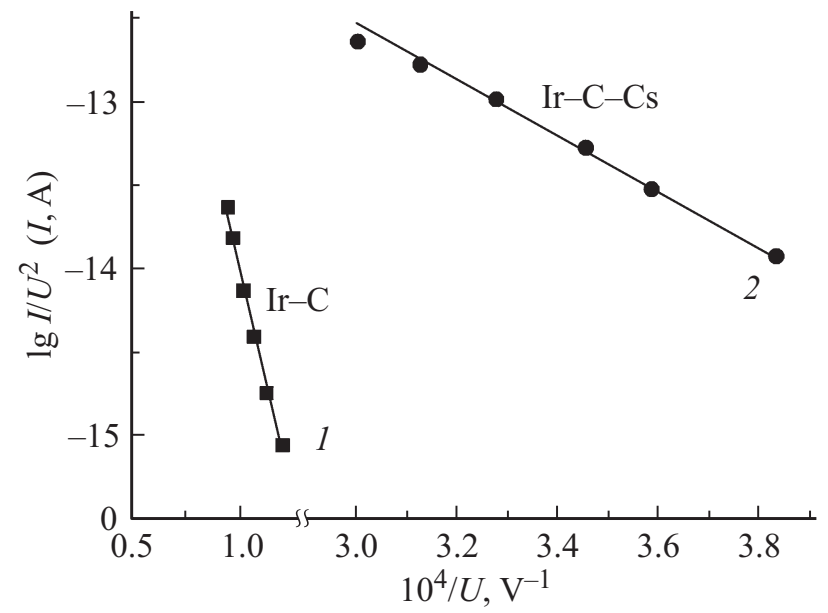

Рис. 2. Вольт-амперные характеристики в координатах Фаулера-Нордгейма.

соответствует распределению напряженности электрического поля: плоские грани, на которых поле слабее, практически не вносят вклад в эмиссию; эмитируют скругленные области острия с большим локальным усилением поля.

Образование графена на плоских поверхностях иридия подтверждается появлением двух фаз полевой десорбции атомов щелочных металлов, предварительно осажденных на поверхность эмиттера [13]. Фазы десорбции регистрируются при постепенном повышении напряженности электрического поля, вызывающего десорбцию. Первая фаза связана с полевой десорбцией атомов щелочных металлов, адсорбированных на поверхности эмиттера, в том числе на поверхности графеновой пленки, а вторая фаза (при более высокой напряженности поля) появлялась вследствие выхода интеркалированных атомов из-под пленки графена и их полевой десорбции. После удаления атомов щелочных металлов с поверхности эмиттера наблюдалась только одна фаза полевой десорбции, совпадающая по напряженности поля со второй фазой, т. е. с десорбцией из интеркалированного состояния. Удаление поверхностных атомов щелочного металла производилось прогревом эмиттера при температуре ниже 1000 и контролировалось по изменению работы выхода. Работа выхода после прогрева возвращалась к работе выхода пленки графена до нанесения щелочного металла (4.3-4.4 eV).

Полевое электронное изображение иридиевого полевого эмиттера с углеродным покрытием после напыления атомов щелочного металла (цезия) в количестве, превышающем необходимое для получения монослойного покрытия, приведено на рис. $1, b$. Атомы щелочных металлов заполняют не только поверхность эмиттера, но и проникают под графеновую пленку, образуя интеркалированное состояние.

На рис. 2 приведены вольт-амперные характеристики полевой электронной эмиссии в координатах Фаулера-
Нордгейма для эмиттера с углеродным покрытием (1) и с адсорбированным цезием (2). Они достаточно хорошо аппроксимируются прямыми линиями. Небольшое отклонение от линейности наблюдается в случае адсорбции атомов щелочных металлов на поверхности (кривая 2) в области сильных электрических полей. Такие отклонения наблюдаются и при адсорбции атомов щелочных металлов на металлах и связаны с небольшим изменением концентрации атомов щелочного металла на поверхности при диффузии в неоднородном электрическом поле [14].

Как следует из полученных полевых электронных изображений и вольт-амперных характеристик полевой электронной эмиссии, интеркалированные атомы щелочного металла, находящиеся под графеном, не оказывают существенного влияния на полевую электронную эмиссию. Если на поверхности графена с интеркалированным щелочным металлом добавочно адсорбировать атомы щелочного металла, то работа выхода существенно снижается (для Cs до $\varphi=2 \mathrm{eV}$, для $\mathrm{Na}$ до $2.3 \mathrm{eV}$ ) и наблюдается полевая эмиссия электронов со всей графеновой пленки на грани (рис. $1, b)$. Учитывая, что в области плоских граней напряженность электрического поля ниже, чем на окружающей поверхности, можно сделать вывод о более сильном снижении работы выхода в области графенового покрытия. Это снижение, вероятно, вызвано переносом электронного заряда и изменением двойного электрического слоя на поверхности в условиях, когда атомы щелочного металла находятся как на поверхности графеновой пленки, так и под ней в интеркалированном состоянии. При этом происходит более сильное изменение двойного электрического слоя на поверхности с графеном по сравнению с поверхностью металла, покрытого углеродом не графеновой фазы, где нет интеркаляции атомов щелочного металла. Таким образом, происходит аномально высокое усиление полевой электронной эмиссии и снижение работы выхода плоских плотноупакованных граней иридиевого полевого эмиттера, покрытых монослойной пленкой графена, при одновременном наличии атомов щелочного металла на поверхности графена и в интеркалированном состоянии под графеном.

\section{2. Образование графита}

Более интенсивные выдержки в парах бензола позволяли получить многослойные структуры углерода на поверхности эмиттера. На рис. 3 приведены примеры полевых электронных изображений иридиевого острия непосредственно после выдержки в парах бензола $\left(p=5 \cdot 10^{-6}\right.$ Torr, $\left.T=1500 \mathrm{~K}, t=4 \mathrm{~min}\right)$. Изображения состоят в основном из светлых прямолинейных полос. Анализ полевых электронных и десорбционных изображений и их изменений при изменениях электрического поля позволяет определить форму вершины острия. Выдержка в парах бензола привела к изменению вершины острия от скругленной формы с небольшими 
по размеру участками плоских граней к форме многогранника (рис. 3,a). Грани многогранника параллельны плоскостям (100) и (111) исходного кристалла иридия. На экране помещается только часть изображения вершины эмиттера. На полном изображении вершины острия (анализируется при поворотах острия) присутствует грань (100), окруженная четырьмя симметрично расположенными гранями (111). Эмиссия электронов и ионов происходит с ребер многогранника, образованных пересечением плотноупакованных плоскостей. На ребрах происходит усиление локального электрического поля. Этот факт подтверждается изменениями вольтамперных характеристик Фаулера-Нордгейма.

В некоторых случаях наблюдалось частичное превращение вершины острия в многогранник. На рис. 3,b приведен пример полевого электронного изображения
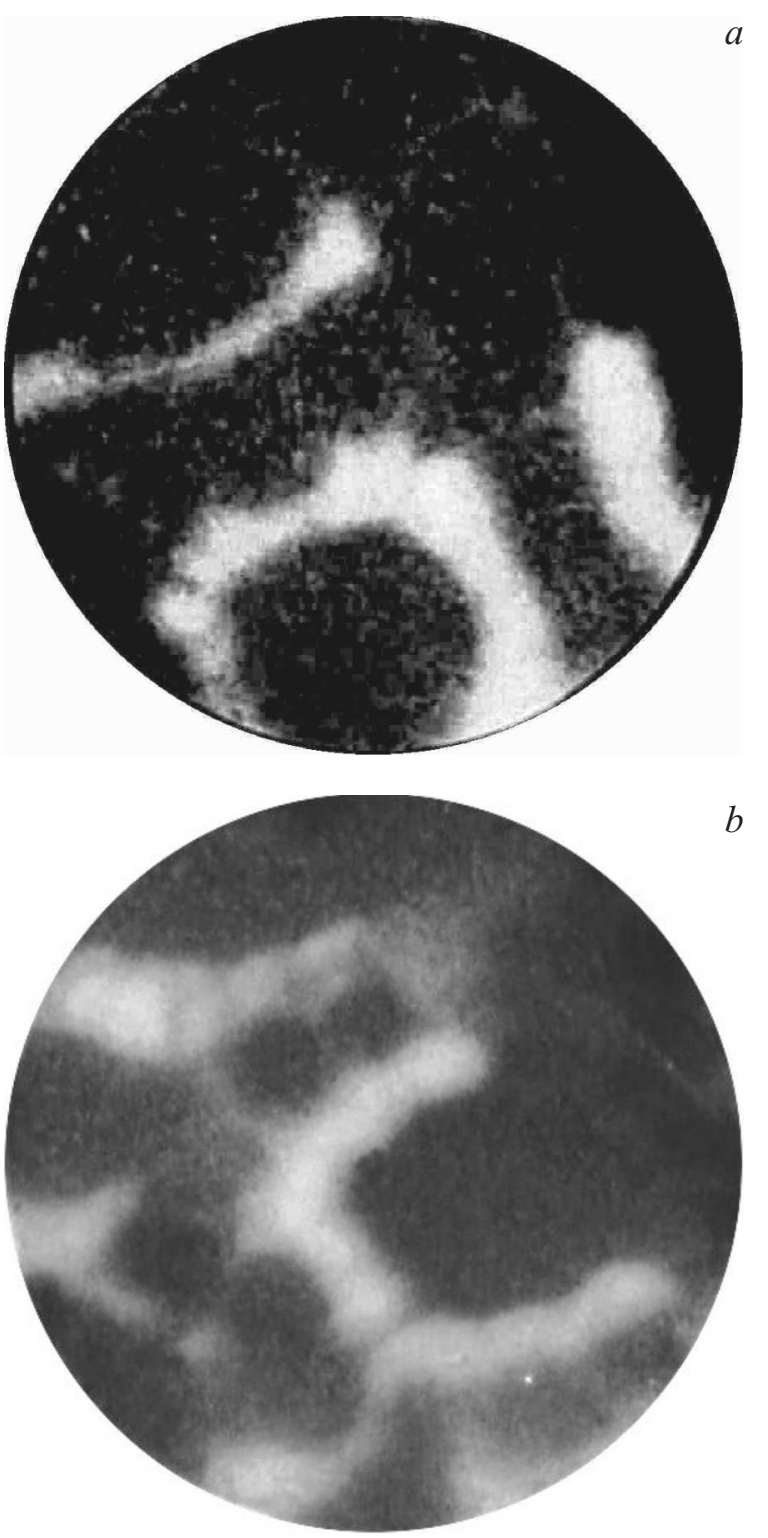

Рис. 3. Полевые электронные изображения иридиевого острия с графитовыми наростами.

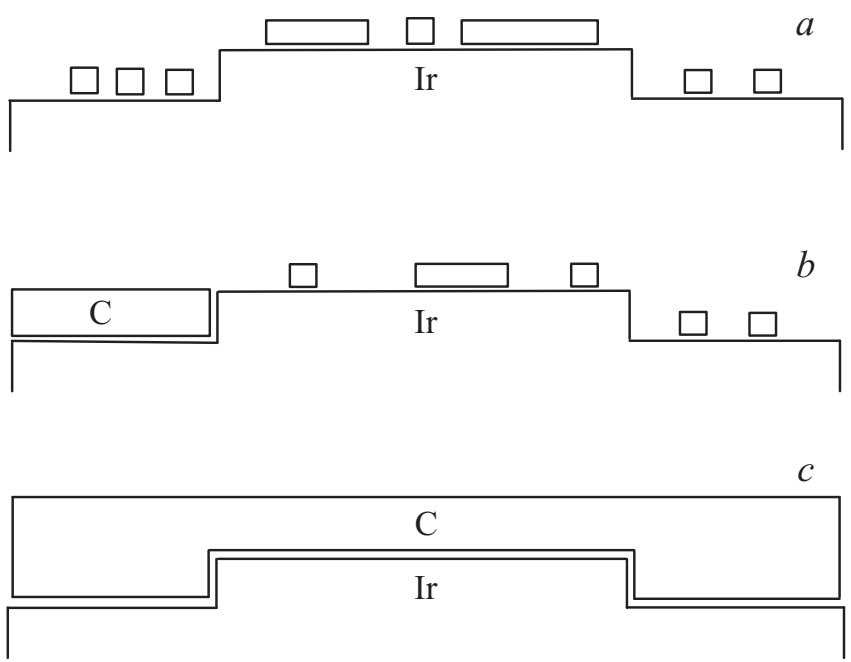

Рис. 4. Схемы, поясняющие рост углеродного покрытия.

острия, часть поверхности которого (три четверти) является поверхностью графитового многогранника, а остальная поверхность осталась скругленной поверхностью иридиевого острия, покрытой атомами углерода.

После напыления щелочных металлов ( $\mathrm{Na}, \mathrm{K}, \mathrm{Cs})$ и последующего удаления их с поверхности нагреванием эмиттера эмиссионное изображение и вольт-амперные характеристик полевой электронной эмиссии возвращаются к состояниям до напыления, что говорит об отсутствии щелочного металла на поверхности. Однако щелочной металл оставался в объеме углеродного покрытия, что проявлялось при полевой десорбции.

\section{3. Обсуждение результатов}

Для объяснения наблюдаемых процессов можно предложить следующую модель. На рис. 4 представлены схемы, поясняющие исследуемые формы и процессы. Образование углеродного покрытия на поверхности металла происходит вследствие каталитической диссоциации молекул, содержащих углерод, и термической десорбции образующихся летучих продуктов. Остающиеся на поверхности атомы углерода формируют углеродное покрытие. На графене диссоциации практически нет. Когда графеновая пленка покрывает всю поверхность, диссоциация и количество освобождающихся атомов углерода уменьшаются на несколько порядков величины $[8,9]$. Углерод на плоских гранях не накапливается изза термической десорбции и поверхностной диффузии на окружающую грани поверхность. Результирующая концентрация углеродных атомов на графене, покрывающем плоские грани, не достаточна для зарождения второго графенового слоя. Поэтому рост углеродного покрытия на плоских плотноупакованных гранях ограничивается либо появлением двумерных островков графена, либо ростом монослойной графеновой пленки, покрывающей грань. 
На острие кроме плоских участков имеются ступени и искривленные участки, которые составляют значительную часть поверхности. Криволинейная форма поверхности с радиусом закругления порядка 10-100 nm не создает условий для формирования плоской пленки графена. На участках поверхности, состоящих из узких моноатомных по высоте ступеней, остаются отдельные атомы углерода, их ассоциации и чистая поверхность иридия. На них продолжается диссоциация бензола и высвобождение атомов углерода. Освобождающиеся при диссоциации атомы углерода могут перемещаться по поверхности и достраивать графеновой слой на плоскости и на широких ступенях (рис. 4,a), образуя несколько слоев графена (графитовый нарост) (рис. 4,b). Графеновые слои растущего на криволинейной поверхности нароста располагаются не параллельно исходной поверхности иридиевого острия, как на плоских гранях, а под углом. Усиление электрического поля на краю нароста вызывает усиленную эмиссию электронов и ионов.

\section{Заключение}

Формирование углеродного покрытия при пиролизе органического вещества на острие отличается от плоских поверхностей, на которых образуется только монослойное покрытие [8]. Острийный эмиттер можно покрывать как монослойным графеном, так и графитом.

На плоских гранях образуется графен. Осаждение щелочных металлов вызывает аномально сильное снижение работы выхода в условиях, когда атомы щелочного металла находятся на поверхности и под пленкой графена. В этом случае полевая электронная эмиссия локализуется на плоских гранях острия.

При определенных условиях можно получить эмиттер, в котором металлическая основа полностью покрыта углеродом в форме графита.

\section{Список литературы}

[1] Шешин Е.П. Структура поверхности и автоэмиссионные свойства углеродных материалов. М.: Изд-во МФТИ, 2001. $288 \mathrm{c}$.

[2] Forbes R.G. // Sol. St. Electron. 2001. Vol. 45. P. 779-808.

[3] Kumar S., Duesberg G.S., Pratap R., Raghavan S. // Appl. Phys. Lett. 2014. Vol. 105. P. 103-107.

[4] Тумарева Т.А., Соминский Г.Г,, Светлов И.А., Морозов А.Н. // ЖТФ. 2008. Т. 78. Вып. 11. С. 119-122.

[5] Тумарева Т.А., Соминский Г.Г. // ЖТФ. 2013. Т. 83. Вып. 7. C. $121-124$.

[6] Соминский Г.Г., Тарадаев Е.П., Тумарева Т.А., Гиваргизов М.Е., Степанова А.Н. // ЖТФ. 2016. Т. 86. Вып. 11. C. $108-111$.

[7] Месяи Г.А. Взрывная электронная эмиссия. М.: Изд-во физ.-мат. лит., 2011. 280 с.

[8] Rut'kov E.V., Gall N.R. In: Physics and Applications of Graphene - Experiments. Ed. S. Mikhailov. Rijeca-L.: Intech OpenAccess Publisher, 2011. P. 209.
[9] Gall N.R., Rut'kov E.V., TontegodeA.Ya. // Int. J. Mod. Phys. B. 1997. Vol. 11. P. 1865-1911.

[10] Бернацкий Д.П., Павлов В.Г. // Письма в ЖТФ. 2016. Т. 42. Вып. 11. С. 105-110.

[11] Бернацкий Д.П., Павлов В.Г. // Известия РАН. Сер. физич. 2009. T. 73. C. 713-715.

[12] Rut'kov E.V., Tontegode A.Ya. // Surf. Sci. 1985. Vol. 161. P. 373.

[13] Бернацкий Д.П., Павлов В.Г. // Письма в ЖТФ. 2015. Т. 40. Вып. 15. С. 40- 45.

[14] Гаврилюк В.М., Наумовеи, А.Г. // ФТТ. 1963. Т. 5. Вып. 10. C. $2792-2798$. 